\title{
Development of a Clinical Nomogram for Prediction of Response to Neoadjuvant Chemotherapy in Patients with Advanced Gastric Cancer
}

\section{Xianwen Liang}

Sichuan University West China Hospital

Xu-Liang Liao

Sichuan University West China Hospital

Hua-Yang Pang

Sichuan University West China Hospital

Tao Pan

Sichuan University West China Hospital

Xiao-Hai Song

Sichuan University West China Hospital

Wei-Han Zhang

Sichuan University West China Hospital

Kai Liu

Sichuan University West China Hospital

Xiao-Long Chen

Sichuan University West China Hospital

Xin-Zu Chen

Sichuan University West China Hospital

Kun Yang

Sichuan University West China Hospital

Jian-Kun Hu ( $\nabla$ hujkwch@126.com )

Sichuan University West China Hospital https://orcid.org/0000-0001-6905-3934

\section{Research Article}

Keywords: Advanced gastric cancer, predictor, neoadjuvant chemotherapy, nomogram, TRG.

Posted Date: August 3rd, 2021

DOI: https://doi.org/10.21203/rs.3.rs-742823/v1 
License: (c) (i) This work is licensed under a Creative Commons Attribution 4.0 International License. Read Full License 


\section{Abstract}

Objective:The efficacy of neoadjuvant chemotherapy (NAC) among advanced gastric cancer (GC) is still a controversial issue. Our aim is to find the factors associated with chemosensitivity of NAC, and provide optimal therapeutic strategy for GC patients who received NAC.

Methods: Clinical information was collected from 230 gastric cancer patients who received NAC in West China Hospital from January 2016 to December 2020. LASSO logistic regression analysis was performed to find the possible predictors which a nomogram model for prediction of response to NAC was based on.

Results: A total of 230 patients were finally included in this study, including 154 males (67.0\%) and 76 females $(33.0 \%)$. And mean age was $(59.37 \pm 10.60)$ years, ranging from 24 to 80 years. Based on the TRG standard, there were 95 cases in the obvious response group (grade 0 or grade 1) and 135 cases in the non-obvious response group (grade 2 or grade 3 ), and the obvious response rate was $41.3 \%$. LASSO analysis showed that four risk factors that were significantly related to the efficacy of NAC, which included tumor location $(P<0.001)$, histological differentiation $(P=0.001)$, clinical T stage $(P=0.008)$, CA724 $(\mathrm{P}=0.008)$. The $\mathrm{C}$-index for prediction nomogram was 0.806 , and the calibration curve revealed the predicted value exhibited good agreement with the actual value, decision curve analysis showed that the nomogram had a good value in clinical application.

Conclusions: The nomogram which combined tumor location, histological differentiation囚clinical T stage and CA724 showed satisfactory predictive power to response of NAC, and could be used by gastrointestinal surgeons to identify optimal treatment strategy for advanced gastric cancer patients.

\section{Introduction}

Gastric cancer (GC) is the fourth most common malignancy in terms of mortality, and results in about 770000 deaths in 2020 [1]. Unfortunately, due to the asymptomatic nature in patients with early gastric cancer, the rate of early diagnosis is very low across the world [2]. The 5-year survival rate of patients with advanced gastric cancer is only $25 \%-31 \%$ [3-6]. Combination with gastrectomy with D2 lymph node dissection and postoperative chemotherapy have modestly improved survival of advanced GC patients, however, the overall survival of patients is still unsatisfactory. In recent years, neoadjuvant chemotherapy (NAC) is recommended as a critical treatment by several national and international guidelines in hope of improving the therapeutic effect in patients with advanced gastric cancer [7-9]. The purposes of NAC are to downstage the tumor and bring likely R0 resection for advanced gastric cancer patients [10]. National Comprehensive Cancer Network (NCCN) guideline (version 2021.1) recommends that patients with clinical TNM stage $\geq T 2 N+$ should receive NAC [8]. The fifth edition of Japanese treatment guidelines recommends that patients with the stage from T2 to T4 and lymph node enlargement should receive NAC [9].

Although NAC can reduce tumor burden, decrease tumor stage, increase the radical resection rate and improve survival outcomes, there are still many controversial points, such as chemotherapy scheme, 
chemotherapy frequency, indications and so on [11]. Some previous studies have demonstrated that the survival advantage of NAC depends on the pathological response of tumor to chemotherapy drugs, which indicate that patients with complete pathological response to neoadjuvant chemotherapy are more likely to have long disease-free survival and overall survival [12-14], while those with limited response to chemotherapy and no significant reduction of tumor after chemotherapy may indicate poor prognosis. For patients with low objective response rate to NAC, the treatment not only delays date of surgery, but also cause serious toxic side effects to patients. Therefore it is very important to predict the sensitivity of NAC for patients with GC and further evaluate whether they are suitable for NAC. For patients with poor sensitivity, surgery or other comprehensive treatment should be carried out as soon as possible. Recently, much effort has been made to identify the predictor of the response to NAC, and nomogram models have been used for the prediction of advanced GC prognosis after NAC [15-19]. Compared with the traditional segmented models, these nomograms showed superior performance. However, most studies have only discussed the prognosis of patients and postoperative complications after NAC, and only few studies identified some predictors that could predict the effect of NAC before chemotherapy.

Therefore, in the present study, we retrospectively analyzed the tumor biological characteristics and clinical parameters that may affect the effect of NAC in patients with advanced GC, and established a nomogram model to predict the response of NAC, so as to provide individualized treatment strategies and maximize the benefits for patients with advanced GC.

\section{Materials And Methods}

\section{Patients and data collection}

We collected the clinical data of 259 advanced GC patients with neoadjuvant chemotherapy from medical records in West China Hospital between January 2016 and December 2020, and conducted a retrospective analysis of the data.Inclusion criteria were as follows: $₫$ patients were diagnosed as GC

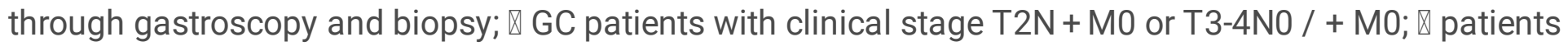
who had completed NAC; $\varangle$ GC patients received radical gastrectomy after neoadjuvant chemotherapy; $\varangle$ the chemotherapy regimens was XELOX; $\otimes$ patients' age was from 18 to 80 years old. And the exclusion criteria included: $\otimes$ preoperative chemotherapy was not completed as planned ( $<3$ cycles); $\otimes$ patients with other malignant tumor diseases; $₫$ patients with gastric stump cancer; $\otimes$ patients have received

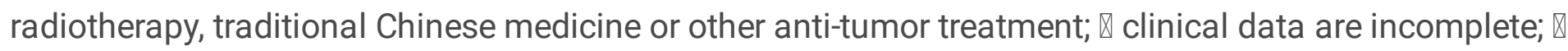
postoperative pathology examination was not adenocarcinoma.

\section{Treatment process}

The patients whose clinical stage was $\mathrm{T} 2 \mathrm{~N}+\mathrm{M} 0$ or T3-4N0 / +M0, were treated with laparoscopic exploration. If no distant metastasis such as intraperitoneal metastasis was found during the operation, and the tumor could be resected, the chemotherapy would be given for 3 cycles on the first or second day after the laparoscopic exploration. Adjustments to dosage were made based on the effectiveness and patient tolerability. Two weeks after the completion of NAC, the resectability of the primary tumor site was 
confirmed again according to endoscopy and enhanced CT examination, and then the surgery was performed. All of these patients who were enrolled received curative tumor resection (total or subtotal gastrectomy, open or laparoscopic surgery) with D2 lymphadenectomy.

\section{Data Collection}

The clinical data collected before NAC in this study include age, gender, BMI, blood group, tumor markers (CEA, CA125, CA199, CA724), tumor location, tumor size, depth of invasion, lymph node metastasis, pathological classification, albumin, platelet count, lymphocytes, neutrophils, monocytes, smoking history. Tumor size, depth of invasion and lymph node metastasis were evaluated on the basis of enhanced CT with laparoscopic exploration before NAC. The curative effect evaluation standard of NAC was based on TRG standard as proposed by National Comprehensive Cancer Network (NCCN) guidelines in 2021 [8]. Grade 0 (Complete response) is defined no viable cancer cells,including lymph cells; Grade 1 (Near complete response) is that single cells or rare small group of cancer cells; Grade 2 (Partial response) is interpreted as residual cancer cells with evident tumor regression but more than single cells or rare small groups of cancer cells; and Grade 3 (Poor or no response) is intermediate extensive residual cancer with no evident tumor regression. We classified grade 0 and grade 1 as obvious response, grade 2 and grade 3 were classified as non-obvious response. Postoperative complications were defined as events occurring within 30 days after surgery, which were assessed by the Clavien-Dindo classification system [20-21]. The adverse events of NAC was based on the National Cancer Institute's Common Terminology Criteria for Adverse Events (version 4.0).

\section{Statistical analysis}

All statistical analyses were performed by SPSS software ver. 22.0 (IBM, Armonk, NY, United States) and $\mathrm{R}$ version 4.0.3 software (The R Foundation for Statistical Computing, Vienna, Austria. www. r-project. org).

Univariate analysis:Parameters that were not normally distributed were expressed in the form of median (upper quartile to lower quartile) and were analyzed by Mann-Whitney test, while normally distributed parameters were expressed in the form of mean \pm standard deviation and were analyzed by Student's Ttest.And categorical variables were analyzed by chi-square test. The test level $a=0.05$.

Multivariate analysis: The least absolute shrinkage and selection operator (LASSO) method was used to select the most useful predictive factors for outcomes of neoadjuvant chemotherapeutic response $(\mathrm{P}<$ 0.05). The regression coefficient and odds ratio with $95 \%$ confidence intervals were estimated.

Nomogram construction:In order to predict the response of NAC, a nomogram including significant prognostic factors was constructed based on logistic regression analysis using glm $\mathrm{R}$ package (version 4.0.3). The consistency index was calculated, and decision curve analysis(DCA) and correction curve were drawn to evaluate the predictive efficiency of the nomogram.

\section{Results}




\section{Baseline and patient Characteristics}

Patient information was listed in Table 1. Due to incomplete clinical data, receiving targeted therapy, pathological results for non-adenocarcinoma, 29 patients were excluded, and a total of 230 patients entered the study,including 154 males (67.0\%) and 76 females (33.0\%), and mean age was $59.37 \pm 10.60$ years, ranging from 24 to 80 years. Based on the TRG standard, there were 95 cases in the obvious response group (grade 0 or grade 1) and 135 cases in the Non-obvious response group (grade 2 or grade 3 ), and the obvious response rate was $41.3 \%$. The cases of depth of invasion T2 or T3 were 71, and T4 were 159.There were 83 patients (36.1\%) whose tumors were at esophagogastric junction. And 180 patients showed positive lymph node metastasis, which counting for $78.3 \%$. 
Table 1

Characteristics of Patients in the Primary and $\mathrm{P}$ value of univariate analysis

\begin{tabular}{|c|c|c|c|c|c|}
\hline Characteristics & & $\begin{array}{l}\text { obvious response } \\
\text { (grade 0/grade 1), } \\
n=95(\%)\end{array}$ & $\begin{array}{l}\text { Non-obvious response } \\
\text { (grade 2/grade 3), } \mathrm{n}= \\
135(\%)\end{array}$ & $t / x^{2}$ & $P$ \\
\hline Age & & $59.88 \pm 10.00$ & $59.00 \pm 11.03$ & -0.62 & 0.535 \\
\hline \multirow[t]{2}{*}{ Sex } & Male & 70 (73.68) & $84(62.22)$ & \multirow[t]{2}{*}{3.31} & \multirow[t]{2}{*}{0.069} \\
\hline & Female & 25 (26.32) & $51(37.78)$ & & \\
\hline BMI & & $22.90 \pm 3.55$ & $22.85 \pm 2.99$ & -0.12 & 0.907 \\
\hline \multirow[t]{2}{*}{ Location } & $\begin{array}{l}\text { Esophagogastric } \\
\text { junction }\end{array}$ & 53 (55.79) & 30 (22.22) & \multirow[t]{2}{*}{27.24} & \multirow[t]{2}{*}{$\begin{array}{l}<.001 \\
0.001\end{array}$} \\
\hline & $\begin{array}{l}\text { Non- } \\
\text { Esophagogastric } \\
\text { junction }\end{array}$ & $42(44.21)$ & 105 (77.78) & & \\
\hline Tumor size, cm & & $5.65 \pm 2.51$ & $5.97 \pm 2.97$ & 0.86 & 0.393 \\
\hline \multirow[t]{3}{*}{$\begin{array}{l}\text { Tumor } \\
\text { differentiation }\end{array}$} & $\begin{array}{l}\text { Well + } \\
\text { Moderately } \\
\text { differentiated }\end{array}$ & 47 (49.47) & $38(28.15)$ & \multirow[t]{3}{*}{10.88} & \multirow[t]{3}{*}{0.001} \\
\hline & $\begin{array}{l}\text { Poorly } \\
\text { differentiated+ }\end{array}$ & $48(50.53)$ & 97 (71.85) & & \\
\hline & Signet ring cell & & & & \\
\hline \multirow[t]{3}{*}{ cT stage } & $\mathrm{T} 2$ & $6(6.32)$ & $4(2.96)$ & \multirow[t]{3}{*}{9.64} & \multirow[t]{3}{*}{0.008} \\
\hline & T3 & 34 (35.79) & $27(20)$ & & \\
\hline & $\mathrm{T} 4$ & $55(57.89)$ & $104(77.04)$ & & \\
\hline \multirow[t]{2}{*}{ cN stage } & NO & 26 (27.37) & $24(17.78)$ & \multirow[t]{2}{*}{3.02} & \multirow[t]{2}{*}{0.083} \\
\hline & $\mathrm{N}+$ & 69 (72.63) & $111(82.22)$ & & \\
\hline \multirow[t]{4}{*}{ Blood type } & Type A & $25(26.32)$ & 42 (31.11) & \multirow[t]{4}{*}{0.84} & \multirow[t]{4}{*}{0.840} \\
\hline & Type B & $27(28.42)$ & 39 (28.89) & & \\
\hline & Type AB & $11(11.58)$ & $13(9.63)$ & & \\
\hline & Type 0 & 32 (33.68) & $41(30.37)$ & & \\
\hline CA724, U/mL & $\leq 6.5$ & 71 (74.74) & 78 (57.78) & 7.03 & 0.008 \\
\hline \multicolumn{6}{|c|}{$\begin{array}{l}\text { BMI: Body Mass Index; CA125: Carbohydrate antigen 125; CEA: Carcinoembryonic antigen; CA724: } \\
\text { Carbohydrate antigen 724; CA125: Carbohydrate antigen 125; CA199: Carbohydrate antigen 199; PLT: } \\
\text { Platelets; PLR: platelet to lymphocyte ratio; NMR:neutrophil to monocyte ratio; NLR: neutrolphil to } \\
\text { lymphocyte ratio. }\end{array}$} \\
\hline
\end{tabular}




\begin{tabular}{|c|c|c|c|c|c|}
\hline \multicolumn{2}{|c|}{ Characteristics } & \multirow{2}{*}{ 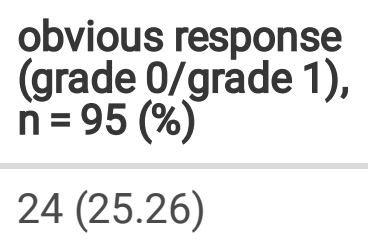 } & \multirow{2}{*}{$\begin{array}{l}\text { Non-obvious response } \\
\text { (grade 2/grade 3), } \mathrm{n}= \\
135(\%) \\
57(42.22)\end{array}$} & \multirow[t]{2}{*}{$t / x^{2}$} & \multirow[t]{2}{*}{$\mathbf{P}$} \\
\hline & $>6.5$ & & & & \\
\hline \multicolumn{2}{|c|}{$\mathrm{CEA}, \mathrm{ng} / \mathrm{mL}$} & $8.19 \pm 24.68$ & $16.15 \pm 88.38$ & 0.85 & 0.394 \\
\hline \multicolumn{2}{|c|}{$\mathrm{CA} 125, \mathrm{U} / \mathrm{mL}$} & $15.05 \pm 9.37$ & $13.17 \pm 7.71$ & -1.67 & 0.097 \\
\hline \multicolumn{2}{|c|}{ CA199, U/mL } & $40.73 \pm 128.33$ & $35.93 \pm 88.46$ & -0.34 & 0.737 \\
\hline \multicolumn{2}{|c|}{ Albumin, g/L } & $\begin{array}{l}41.77(41.01- \\
42.52)\end{array}$ & $41.64(40.98-42.29)$ & -0.25 & 0.803 \\
\hline \multicolumn{2}{|c|}{$\mathrm{PLT}, 10^{9} / \mathrm{L}$} & $224.56 \pm 95.13$ & $214.83 \pm 73.90$ & -0.87 & 0.384 \\
\hline \multicolumn{2}{|c|}{ Lymphocyte, $10^{9} / \mathrm{L}$} & $1.57 \pm 0.51$ & $1.59 \pm 0.44$ & 0.25 & 0.806 \\
\hline \multicolumn{2}{|l|}{ PLR } & $153.65 \pm 70.73$ & $144.45 \pm 64.21$ & -1.03 & 0.306 \\
\hline \multicolumn{2}{|c|}{ Neutrophil cell, $10^{9} / \mathrm{L}$} & $3.65 \pm 1.43$ & $3.57 \pm 1.36$ & -0.47 & 0.637 \\
\hline \multicolumn{2}{|c|}{ Monocyte, $10^{9} / \mathrm{L}$} & $0.43 \pm 0.16$ & $0.41 \pm 0.14$ & -1.19 & 0.235 \\
\hline \multicolumn{2}{|l|}{ NMR } & $9.07 \pm 3.98$ & $9.24 \pm 3.50$ & 0.346 & 0.730 \\
\hline \multicolumn{2}{|l|}{ NLR } & $2.29(2.26-2.73)$ & $2.41(2.21-2.62)$ & -0.48 & 0.629 \\
\hline \multirow{2}{*}{$\begin{array}{l}\text { Smoking } \\
\text { history }\end{array}$} & yes & 36 (37.89) & $50(37.04)$ & \multirow[t]{2}{*}{0.02} & \multirow[t]{2}{*}{0.895} \\
\hline & no & $59(62.11)$ & $85(62.96)$ & & \\
\hline \multicolumn{6}{|c|}{$\begin{array}{l}\text { BMI: Body Mass Index; CA125: Carbohydrate antigen 125; CEA: Carcinoembryonic antigen; CA724: } \\
\text { Carbohydrate antigen 724; CA125: Carbohydrate antigen 125; CA199: Carbohydrate antigen 199; PLT: } \\
\text { Platelets; PLR: platelet to lymphocyte ratio; NMR:neutrophil to monocyte ratio; NLR: neutrolphil to } \\
\text { lymphocyte ratio. }\end{array}$} \\
\hline
\end{tabular}

\section{Factors of NAC response}

Univariable associations between the clinical parameters and response of NAC were shown in Table 1. Statistically significant factors $(P<0.05)$ included tumor location, differentiation, clinical $T$ stage and CA724. The results showed that the tumor locating in the esophagogastric junction displayed better efficacy than that of non-esophagogastric junction, and greater differentiation level (well/moderate vs. poor differentiation), lower T stage (T2/T3 vs. T4 stage) and lower CA724 level were associated with a better NAC efficacy.

In order to avoid the multicollinearity problem in regression analysis, the distribution coefficient was analyzed by LASSO regression with an elastic net penality. The results of LASSO regression analysis were the same with those of univariate analysis, and four independent predictors including tumor location, differentiation, clinical T stage and CA724 were included in the final model, as shown in Fig. 1. 
The model that incorporated the above independent predictors was developed and presented as the nomogram (Fig. 2). The C-index for the prediction nomogram was 0.806 indicating the prediction performance of this nomogram was quite good. The calibration curve of the NAC nomogram demonstrated a good agreement between prediction and actual observations in the primary cohort (Fig. 3). And the value of the nomogram and its use in the clinic was evaluated by the DCA, which evaluated the value in terms of clinic application for the NAC nomogram (Fig. 4).

\section{Toxicity of NAC}

Based on the National Cancer Institute's Common Terminology Criteria for Adverse Events, version 4.0, the overall incidence of NAC adverse events was $85.7 \%$, and the rate of grade $3 / 4$ toxicity was $33.48 \%$. The main side effects were hematological toxicity and gastrointestinal reaction. And anemia (15.7\%) was the most common grade 3/4 adverse events (Table 2). In addition, we found that in the Gastrointestinal, the hematological and the neurological system, the incidence of adverse reaction in the group with nonobvious response was slightly higher than that in the group with obvious response, even though the differences were not statistically significant $(P>0.05)$, as show in Table 3.

Table 2

Toxicity of NAC

\begin{tabular}{|llll|}
\hline & Grade 1/2, $\mathbf{n = 1 2 0}(\%)$ & Grade 3/4, $\mathbf{n}=\mathbf{7 7}(\%)$ & Total, $\mathbf{n = 1 9 7}$ \\
\hline Anemia & $107(89.17)$ & $36(46.75)$ & $143(72.59)$ \\
\hline Leukopenia & $33(27.50)$ & $20(25.97)$ & $53(26.90)$ \\
\hline Neutropenia & $25(20.83)$ & $6(7.79)$ & $31(15.74)$ \\
\hline Thrombocytopenia & $27(22.50)$ & $17(22.08)$ & $44(22.34)$ \\
\hline Nausea/vomiting & $57(47.50)$ & $12(15.58)$ & $69(35.03)$ \\
\hline Diarrhea & $12(10.00)$ & $1(1.30)$ & $13(6.60)$ \\
\hline Hepatic impairment & $21(17.50)$ & $10(13.00)$ & $31(15.74)$ \\
\hline Hand-Foot Syndrome & $39(32.50)$ & 0 & $39(19.80)$ \\
\hline Cardiotoxicity & $1(0.83)$ & 0 & $1(0.51)$ \\
\hline
\end{tabular}


Table 3

Comparison of toxicity between obvious response group and non-obvious response group

\begin{tabular}{|llllll|}
\hline & $\begin{array}{l}\text { Total, } \mathbf{n}= \\
\mathbf{2 3 0}(\mathbf{\%})\end{array}$ & $\begin{array}{l}\text { Obvious response, } \mathbf{n} \\
\mathbf{= 9 5 ( \% )}\end{array}$ & $\begin{array}{l}\text { Non-obvious response, } \\
\mathbf{n = 1 3 5 ( \% )}\end{array}$ & $\mathbf{\chi 2}$ & $\mathbf{p}$ \\
\hline Gastrointestinal & $91(39.57)$ & $41(43.16)$ & $50(37.04)$ & 0.874 & 0.350 \\
\hline Hematological & $169(73.48)$ & $71(74.74)$ & $98(72.59)$ & 0.132 & 0.717 \\
\hline Neurological & $39(16.96)$ & $19(20.00)$ & $20(14.81)$ & 1.065 & 0.302 \\
\hline Cardiac & $1(0.43)$ & $1(1.05)$ & 0 & 1.385 & 0.239 \\
\hline
\end{tabular}

\section{Postoperative complications}

In this study, 51 patients (22.2\%) suffered from postoperative complications, and most of them were Clavien-Dindo grade 2 complication. The most common complications were pulmonary infection and pleural effusion (15.2\%). And 1 patient died of anastomotic leakage and abdominal hemorrhage. There was no statistical difference in the incidence of each complication between the obvious response group and the non-obvious response group. Detailed information were listed in Table 4 and Table 5. 
Table 4

Postoperative complications after NAC(Clavien-Dindo classification)

\begin{tabular}{|c|c|c|c|c|c|c|c|}
\hline & $\begin{array}{l}\text { Grade } \\
1, n=2 \\
(\%)\end{array}$ & $\begin{array}{l}\text { Grade } \\
2, n=43 \\
(\%)\end{array}$ & $\begin{array}{l}\text { Grade } \\
3 a, n=5 \\
(\%)\end{array}$ & $\begin{array}{l}\text { Grade } \\
3 b, n=0 \\
(\%)\end{array}$ & $\begin{array}{l}\text { Grade 4a, } \\
\mathrm{n}=0(\%)\end{array}$ & $\begin{array}{l}\text { Grade4b, } \\
\mathrm{n}=0(\%)\end{array}$ & $\begin{array}{l}\text { Grade 5, } \\
n=1(\%)\end{array}$ \\
\hline $\begin{array}{l}\text { Pulmonary } \\
\text { infection/ }\end{array}$ & 0 & $\begin{array}{l}31 \\
(72.09)\end{array}$ & $4(80)$ & 0 & 0 & 0 & 0 \\
\hline \multicolumn{8}{|l|}{$\begin{array}{l}\text { Pleural } \\
\text { effusion }\end{array}$} \\
\hline $\begin{array}{l}\text { Incision } \\
\text { infection }\end{array}$ & $2(100)$ & 0 & 0 & 0 & 0 & 0 & 0 \\
\hline $\begin{array}{l}\text { Intraperitoneal } \\
\text { hemorrhage }\end{array}$ & 0 & 0 & 0 & 0 & 0 & 0 & $1(100)$ \\
\hline $\begin{array}{l}\text { Digestive tract } \\
\text { hemorrhage }\end{array}$ & 0 & $2(4.65)$ & 0 & 0 & 0 & 0 & 0 \\
\hline $\begin{array}{l}\text { anastomotic } \\
\text { leakage }\end{array}$ & 0 & 0 & $1(20)$ & 0 & 0 & 0 & $1(100)$ \\
\hline $\begin{array}{l}\text { Duodenal } \\
\text { stump fistula }\end{array}$ & 0 & $2(4.65)$ & 0 & 0 & 0 & 0 & 0 \\
\hline Gastroplegia & 0 & $3(6.98)$ & 0 & 0 & 0 & 0 & 0 \\
\hline $\begin{array}{l}\text { Intestinal } \\
\text { obstruction }\end{array}$ & 0 & $3(6.98)$ & 0 & 0 & 0 & 0 & 0 \\
\hline $\begin{array}{l}\text { Peritoneal } \\
\text { effusion/ }\end{array}$ & 0 & $4(9.30)$ & 0 & 0 & 0 & 0 & $1(100)$ \\
\hline \multicolumn{8}{|l|}{$\begin{array}{l}\text { Abscess } \\
\text { formation }\end{array}$} \\
\hline $\begin{array}{l}\text { Lymphatic } \\
\text { leakage }\end{array}$ & 0 & $1(2.33)$ & 0 & 0 & 0 & 0 & 0 \\
\hline $\begin{array}{l}\text { Urinary tract } \\
\text { infection }\end{array}$ & 0 & $3(6.98)$ & 0 & 0 & 0 & 0 & 0 \\
\hline
\end{tabular}


Table 5

Comparison of postoperative complications between obvious response group and non-obvious response group

\begin{tabular}{|c|c|c|c|c|}
\hline & $\begin{array}{l}\text { Obvious-response, } \mathrm{n}= \\
95(\%)\end{array}$ & $\begin{array}{l}\text { Non-obvious-response, } \mathrm{n}= \\
135(\%)\end{array}$ & $x^{2}$ & $p$ \\
\hline $\begin{array}{l}\text { Pulmonary infection/ } \\
\text { Pleural effusion }\end{array}$ & $17(17.89)$ & $18(13.33)$ & 0.899 & 0.343 \\
\hline Incision infection & 0 & $1(0.74)$ & 0.00 & $\overrightarrow{0.99}$ \\
\hline $\begin{array}{l}\text { Intraperitoneal } \\
\text { hemorrhage }\end{array}$ & $1(1.05)$ & 0 & 0.031 & 0.860 \\
\hline $\begin{array}{l}\text { Digestive tract } \\
\text { hemorrhage }\end{array}$ & $2(2.11)$ & 0 & 0.945 & 0.331 \\
\hline anastomotic leakage & $1(1.05)$ & $1(0.74)$ & 0.000 & $\overrightarrow{0.99}$ \\
\hline $\begin{array}{l}\text { Duodenal stump } \\
\text { fistula }\end{array}$ & 0 & $2(1.48)$ & 0.221 & 0.638 \\
\hline Gastroplegia & $1(1.05)$ & $2(1.48)$ & 0.095 & 0.758 \\
\hline Intestinal obstruction & $1(1.05)$ & $2(1.48)$ & 0.000 & $\overrightarrow{0.99}$ \\
\hline $\begin{array}{l}\text { Peritoneal effusion/ } \\
\text { Abscess formation }\end{array}$ & $1(1.05)$ & $4(2.96)$ & 0.269 & 0.604 \\
\hline Lymphatic leakage & 0 & $1(0.74)$ & 0.000 & $\overrightarrow{0.99}$ \\
\hline Urinary tract infection & $2(2.11)$ & $1(0.74)$ & 0.095 & 0.758 \\
\hline
\end{tabular}

\section{Discussion}

Surgery is the most important treatment for GC. More than $60 \%$ of patients have reached advanced stage at the time of diagnosis, which led to low radical resection rate ,therefore an efficient method for increasing the radical resection rate is urgently needed in the clinic [22].

Previous studies have demonstrated that surgery was capable of inducing tumor cells to transform into drug-resistant clones and increasing the production of tumor growth stimulating factors which can promote tumor cell proliferation. In early stage, the number of tumor cells is small, cell proliferation and DNA replication are active, at this time, tumor cells are more sensitive to chemotherapeutic drugs [23]. Therefore, chemotherapy drugs given before tumor resection can not only kill the primary tumor, but also inhibit the growth stimulating factors of cancer cells, which is also effective for micrometastases. The 
earlier chemotherapy, the fewer drug-resistant cell lines [24]. Which highlights the importance of neoadjuvant chemotherapy.

Presently, increasing attention is being paid to preoperative chemotherapy. The role of NAC is to help surgeon in decreasing the primary tumor size and stage, eliminating micrometastasis, alleviating tumor related symptoms, improving curative resection rate and reducing postoperative recurrence. However, some patients who are not sensitive to chemotherapy drugs cannot benefit from NAC, resulting in tumor progression and the time delay of surgical resection. Studies have shown that nearly $15 \%$ of patients receiving preoperative neoadjuvant therapy have the risk of tumor progression [25]. Moreover, patients often suffer from side effects of NAC including cardiotoxicity, hepatotoxic and nephrotoxicity, which increase the risk of complications and mortality when surgery is performed. Therefore, it is particularly important to predict the efficacy of NAC. Thus, we set up an exploratory study to identify pre-treatment parameters that can predict sensitivity to NAC, so as to provide basis for individualized treatment of gastric cancer patients. For patients with promising responsiveness to NAC, neoadjuvant chemotherapy should be considered, otherwise surgery or other comprehensive treatment should be performed as soon as possible.

Our data showed that the obvious response rate of NAC for advanced gastric cancer was $41.3 \%$, which further indicated that only a portion of patients can benefit from NAC, thereby emphasizing the importance of predicting the responses to NAC. According to the results of the univariate and multivariate analysis, we found that tumor location, differentiation, depth of invasion and CA724 were significant influencing factors for predicting the response of NAC. By using the four factors, we constructed a nomogram for predicting the NAC response before performing gastrectomy with lymph node dissection.

A Germany retrospective cohort study including 410 patients indicated that tumor in the upper two-thirds of stomach tend to have a better response to NAT [26]. Study by Li et al. also showed a similar finding [27], which was consistent with our result-the obvious response rate of NAC in patients with tumor locating in esophagogastric junction (63.86\%) was higher than that in patients without tumor locating in esophagogastric junction tumor $(28.57 \%)$, and the difference was statistically significant $(P<0.05)$.

There were many studies had explored that serum tumor markers were associated with diagnosis, prognosis and therapeutic effect of preoperative or postoperative chemotherapy in gastric cancer [28, 29]. Other studies had shown that, CA724 was an independent factor for efficacy of NAC in gastric cancer [30]. Our study reached the same conclusion that the higher the level of CA724, the worse the response to NAC. However, another paper suggested that the sensitivity of CA724 was only approximately $45.0 \%$ [31], and in addition, CA724 was associated with $\mathrm{H}$. pylori infection and environmental factors [32, 33]. These findings implied that there might be a bias to evaluate the patients' condition only depending on CA724, there are still many works that should be done to solve this problem.

Patients with well-differentiated had better survival than those with poorly differentiated in GC [34, 35], and previous studies suggested that differentiation is an important predictor of pathological response $[36,37]$, which is consistent with our study. However, different from the previous studies [38], our results 
show that patients with lower $\mathrm{T}$ stage $(\mathrm{T} 2, \mathrm{~T} 3)$ had better response to neoadjuvant chemotherapy than advanced T stage (T4). Because NAC regimens bring relatively serious toxic and side effects in patients, which damage hematological, digestive, and nervous systems [10]. In this study, the overall incidence of NAC adverse reactions was $85.7 \%$, the rate of grade $3 / 4$ toxicity was $33.48 \%$, therefore, it is important to select the optimal treatment options for different patients, we suggest that for these patients who are not sensitive to NAC, one solution is to apply other regimens of NAC, such as FLOT (fluorouracil plus leucovorin, oxaliplatin, and docetaxel), which resulted in superior OS compared with ECX [39]. And the other is to implement surgery as soon as possible to avoid useless time interval of chemotherapy and surgery when radical resection is available.

In addition, it should be mentioned that in recent years, many studies have focused on the relationship between serum inflammatory factors and tumor, these findings suggest that, in the tumor microenvironment, platelets, neutrophils and lymphocytes take important parts in tumor progression and metastasis due to the production of inflammatory cytokines and chemokines [40-45]. The increase of the number of neutrophils and platelets and the decrease of lymphocytes usually indicate enhanced inflammatory response and impaired immune activity, which may promote tumor cell proliferation, invasion, lymph node metastasis and distant organ metastasis. However, our study suggests that inflammatory factors such as platelets, neutrophils and lymphocytes are not independent predictor of chemosensitivity.

Although a nomogram predicting the response of NAC had been established with C index of 0.767 [10], our study achieved a C-index of 0.806 which indicated a better performance on prediction than previously reported study.

At the same time, we have to admit that our study has some limitations. On the one hand, the results may be biased due to the retrospective design of our study. On the other hand, because most patients enrolled in the study were in the recent 2 years, there were insufficient survival events to analyze the impact of the predictor and chemosensitivity on overall survival rate. Therefore, a high-quality research with a larger cohort of patients is warranted to address this issue.

\section{Conclusions}

Four risk factors that were significantly related to response of NAC, which included tumor location, differentiation, Clinical T stage, CA724. The nomogram we had established exhibit satisfactory predictive power to response of NAC, and can be used by gastrointestinal surgeons to identify optimal treatment strategy for advanced gastric cancer patients.

\section{Abbreviations}

GC 
Gastric cancer; NAC:neoadjuvant chemotherapy; DFS:disease-free survival; OS:overall survival; BMI:Body Mass Index; CA125:Carbohydrate antigen 125; CEA:Carcinoembryonic antigen; CA724:Carbohydrate antigen 724; CA125:Carbohydrate antigen 125; CA199:Carbohydrate antigen 199; PLT:Platelets; PLR:platelet to lymphocyte ratio; NMR:neutrophil to monocyte ratio; NLR:neutrolphil to lymphocyte ratio.

\section{Declarations}

\section{Acknowledgments}

The authors thank Volunteer Team of Gastric Cancer Surgery (VOLTGA) West China Hospital, Sichuan University, China for the substantial work in data collection and follow-up of the database.

\section{Author contributions}

Xian-Wen Liang, Xu-Liang Liao and Hua-Yang Pang: Paper writing and data analysis; Kai-Liu and Wei-Han Zhang: Data collection; Xin-Zu Chen and Kun-Yang: Patient follow-up; Tao-Pan, Xiao-Hai Song: Database establishment; Xiao-Long Chen and Jian-Kun Hu: Supervision and paper revision.

\section{Funding}

This study was funded by (1) National Natural Science Foundation of China, No. 81702366; (2) Sichuan Science and Technology Program, No.2019YFS0255; (3) Sichuan Science and Technology Program, No.20YYJC3357.

\section{Data availability statement}

The data that support the results of this research is available on request from the corresponding author. Considering privacy or ethical restrictions, the data is not publicly available.

\section{Ethics approval and consent to participate}

Patient records were de-identified and anonymized prior to analysis. The Research Ethics Committee of West China Hospital approved this retrospective study and Surgical Gastric Cancer Patient Registry number was (No.WCH-SGCPR-2021-01).

\section{Informed consent}

Informed consent was waived due to the retrospective nature of the analysis.

\section{Consent for publication}

Not applicable.

\section{Conflicts of interest}


The authors indicate no potential conflicts of interest.

\section{References}

1. Sung H, Ferlay J, Siegel RL, Laversanne M, Soerjomataram I, Jemal A, Bray F: Global cancer statistics 2020: GLOBOCAN estimates of incidence and mortality worldwide for 36 cancers in 185 countries. CA Cancer J Clin. 2021;71(3):209-249.

2. Sitarz R, Skierucha M, Mielko J, Offerhaus JA, Maciejewski R, Polkowski WP. Gastric cancer. epidemiology, prevention, classification, and treatment. Cancer Manag Res. 2018;10:239-248.

3. De Angelis R, Sant M, Coleman MP, Francisci S, Baili P, Pierannunzio D, et al. Cancer survival in Europe 1999-2007 by country and age: results of EUROCARE-5-a population-based study. Lancet Oncol. 2014; 15: 23-34.

4. Ren G,Cai R,Zhang WJ,et al.Prediction of risk factors for lymph node metastasis in early gastric cancer. World J Gastroenterol. 2013, 19(20): 3096-3107.

5. Ajani JA, D'Amico TA, Almhanna K, Bentrem DJ, Chao J, Das P, et al. Gastric Cancer, Version 3.2016, NCCN Clinical Practice Guidelines in Oncology. J Natl Compr Canc Netw. 2016, 14(10): 1286-1312.

6. Allemani C, Matsuda T, Di Carlo V, Harewood R, Matz M, Nikšić M, et al. Global surveillance of trends in cancer survival 2000-14 (CONCORD-3): analysis of individual records for 37513025 patients diagnosed with one of 18 cancers from 322 population-based registries in 71 countries. Lancet. 2018, 391(10125): 1023-1075.

7. Wang Y, Zhang J, Guo S, Meng XY, Zheng ZC, Zhao Y: Indications of neoadjuvant chemotherapy for locally advanced Gastric Cancer patients based on pre-treatment clinicalpathological and laboratory parameters. J Cancer. 2020, 11(20):6000-6008.

8. National Comprehensive Cancer Network. Clinical practice guidelines in oncology - gastric cancer: Gastric Cancer (2021.V1) [EB/OL] [2021-03-03].

9. Japanese Gastric Cancer Association. Japanese gastric cancer treatment guidelines 2018 (5th edition). Gastric Cancer. 2021, 24(1):1-21.

10. Chen Y, Xiao J, Chen X, Wang H, Liu D, Xiang J, Peng J: Nomogram for predicting pathological complete response to neoadjuvant chemotherapy in patients with advanced gastric cancer. World Journal of Gastroenterology. 2020, 26(19):2427-2439.

11. Reddavid R, Sofia S, Chiaro P, Colli F, Trapani R, Esposito L, Solej M, Degiuli M. Neoadjuvant chemotherapy for gastric cancer. Is it a must or a fake? World J Gastroenterol. 2018, 24(2): 274289.

12. Lowy AM, Mansfield PF, Leach SD, Pazdur R, Dumas P, Ajani JA. Response to neoadjuvant chemotherapy best predicts survival after curative resection of gastric cancer. Ann Surg. 1999, 229:303-308.

13. Achilli P, De Martini P, Ceresoli M, Mari GM, Costanzi A, Maggioni D, Pugliese R, Ferrari G. Tumor response evaluation after neoadjuvant chemotherapy in locally advanced gastric adenocarcinoma: a 
prospective, multi-center cohort study. J Gastrointest Oncol. 2017, 8: 1018-1025.

14. Lorenzen S, Thuss-Patience P, Al-Batran SE, Lordick F, Haller B, Schuster T, Pauligk C, Luley K, Bichev $D$, Schumacher $G$, Homann N. Impact of pathologic complete response on disease-free survival in patients with esophagogastric adenocarcinoma receiving preoperative docetaxel-based chemotherapy. Ann Oncol. 2013, 24: 2068-2073.

15. Lai J, Pan Z, Chen P, Ye G, Chen K, Su F. Development and validation of a nomogram incorporating axillary lymph node ratio to predict survival in node-positive breast cancer patients after neoadjuvant chemotherapy. Jpn J Clin Oncol. 2019, 49(1):22-28.

16. Lai J, Wang H, Peng J, Chen P, Pan Z. Establishment and external validation of a prognostic model for predicting disease-free survival and risk stratification in breast cancer patients treated with neoadjuvant chemotherapy. Cancer Manag Res. 2018, 10: 2347-2356.

17. Kim CH, Yeom SS, Lee SY, Kim HR, Kim YJ, Lee KH, et al. Prognostic Impact of Perineural Invasion in Rectal Cancer After Neoadjuvant Chemoradiotherapy. World J Surg. 2019, 43(1): 260-272.

18. Tan W, Yang M, Yang H, Zhou F, Shen W. Predicting the response to neoadjuvant therapy for earlystage breast cancer. tumor-, blood-, and imaging-related biomarkers. Cancer Manag Res. 2018, 10: 4333-4347.

19. Zhu YL, Sun YK, Xue XM, Yue JY, Yang L, Xue LY. Unnecessity of lymph node regression evaluation for predicting gastric adenocarcinoma outcome after neoadjuvant chemotherapy. World J Gastrointest Oncol. 2019, 11: 48-58.

20. Clavien PA, Sanabria JR, Strasberg SM. Proposed classification of complications of surgery with examples of utility in cholecystectomy. Surgery. 1992;111(5):518-526.

21. Clavien PA, Sanabria JR, Strasberg SM. Proposed classification of complications of surgery with examples of utility in cholecystectomy. Surgery. 1992;111(5):518-526.

22. Liu X, Cai $H$, Sheng $W$, et al. microRNAs expression profile re- lated with response to preoperative radiochemotherapy in patients with locally advanced gastric cancer [J]. BMC Cancer. 2018, 18(1): 1048.

23. Crookes $P, L$ eichman CG, Leichman L,et al. Systemic chemotherapy for gastric carcinoma followed by postoperative intraperitoneal therapy. a fifi nal report. Cancer. 1997, 79(9): 1767-1775.

24. Lowy AM,Mansfifi eld PF,Leach $S D$,et al. Response to neoadjuvant chemotherapy best predicts survival after curative resection of gastric cancer[J]. Ann Surg. 1999, 229(3): 303-308.

25. Zhou J, Shen J, Seifer BJ, et al. Approaches and genetic determinants in predicting response to neoadjuvant chemotherapy in locally advanced gastric cancer [J]. Oncotarget.2017, 8(18): 3047730494.

26. Lorenzen S, Blank S, Lordick F, Siewert JR, Ott K. Prediction of response and prognosis by a score including only pretherapeutic parameters in 410 neoadjuvant treated gastric cancer patients. Ann Surg Oncol. 2012, 19: 2199 - 2127.

27. Li ZY, Koh CE, Bu ZD, Wu AW, Zhang LH, Wu XJ, et al. Neoadjuvant chemotherapy with FOLFOX: improved outcomes in Chinese patients with locally advanced gastric cancer. J Surg Oncol. 2012, 
105(8): 793-799.

28. Shimada H, Noie T, Ohashi M, Oba K, Takahashi Y. Clinical significance of serum tumor markers for gastric cancer. a systematic review of literature by the task force of the Japanese gastric Cancer association. Gastric Cancer. 2014, 17(1):26-33.

29. Matsuoka T, Yashiro M. Biomarkers of gastric cancer. current topics and future perspective. World J Gastroenterol. 2018, 24(26):2818-2832.

30. Tong Y, Zhao Y, Shan Z, Zhang J: CA724 predicts overall survival in locally advanced gastric cancer patients with neoadjuvant chemotherapy. BMC cancer. 2021, 21(1):4.

31. Ning S, Wei W, Li J, Hou B, Zhong J, Xie Y, Liu H, Mo X, Chen J, Zhang L. Clinical significance and diagnostic capacity of serum TK1, CEA, CA 19 - 9 and CA 72 - 4 levels in gastric and colorectal cancer patients. J Cancer. 2018, 9(3):494-501.

32. Hu PJ, Chen MY, Wu MS, Lin YC, Shih PH, Lai CH, Lin HJ. Clinical Evaluation of CA72-4 for Screening Gastric Cancer in A Healthy Population: A Multicenter Retrospective Study. Cancers (Basel). 2019, $17(5): 733$.

33. Jing J, Ge M, Yang Z, Li P. Spatial distribution characteristics of tumor marker CA724 reference values in China. Cancer Med. 2019, 8(9):4465-4474.

34. Lazar D, Taban S, Sporea I, Dema A, Cornianu M, Lazar E, et al. Gastric cancer. correlation between clinicopathological factors and survival of patients (III). Rom J Morphol Embryol Rev Rom Morphol Embryol. 2009, 50(3):369-379.

35. Kim S, Min B, Ahn J, Jung S, An J, Choi M, et al. Nomogram to predict lymph node metastasis in patients with early gastric cancer. a useful clinical tool to reduce gastrectomy after endoscopic resection. Endoscopy. 2020, 52(6):435-443.

36. Wang $L$, Teng R, Jiang Z, Hu W, Dong M, Yuan X, et al. Clinicopathologic variables predicting tumor response to neoadjuvant chemotherapy in patients with locally advanced gastric cancer. J Surg Oncol.2012, 105(3):293-296.

37. Xu W, Ma Q, Wang L, He C, Lu S, Ni Z, Hua Z, Zhu Z, Yang Z, Zheng Y et al: Prediction Model of Tumor Regression Grade for Advanced Gastric Cancer After Preoperative Chemotherapy. Frontiers in oncology. 2021, 11:607640.

38. Ito S, Sano T, Mizusawa J, Takahari D, Katayama H, Katai H, et al. A phase II study of preoperative chemotherapy with docetaxel, cisplatin, and S-1 followed by gastrectomy with D2 plus para-aortic lymph node dissection for gastric cancer with extensive lymph node metastasis: JCOG1002. Gastric Cancer. 2017, 20: $322-231$.

39. Al-Batran SE, Homann N, Pauligk C, et al. Perioperative chemotherapy with fluorouracil plus leucovorin, oxaliplatin, and docetaxel versus fluorouracil or capecitabine plus cisplatin and epirubicin for locally advanced, resectable gastric or gastro-oesophageal junction adenocar cinoma (FLOT4): a randomised, phase2/3 trial. Lancet. 2019, 393:1948-1957.

40. Kuol N, Stojanovska L, Apostolopoulos V, et al. Crosstalk between cancer and the neuroimmune system[J]. J Neuroimmunol, 2018, 315: 15-23. 
41. Huong PT,Nguyen $L T$, Nguyen $X B$,et al. The role of platelets in the tumor-microenvironment and the drug resistance of cancer cells[J].Cancers(Basel),2019,11(2):240.

42. $X u X R$,Zhang $D, O$ swald $B E$,et al. Platelets are versatile cells: new discoveries in hemostasis, thrombosis,immune responses, tumor metastasis and beyond[J].Crit Rev Clin Lab Sci. 2016, 53(6):409-430.

43. Haemmerle $M$,Stone RL,Menter $D G$,et al. The platelet lifeline to cancer. challenges and opportunities[J]. Cancer Cell, 2018, 33(6):965-983.

44. Felix K, Gaida M: Neutrophil-Derived Proteases in the Microenvironment of Pancreatic Cancer-Active Players in Tumor Progression. International journal of biological sciences. 2016, 12(3):302-313

45. Sano T, Coit D, Kim H, Roviello F, Kassab P, Wittekind C, Yamamoto Y, Ohashi Y: Proposal of a new stage grouping of gastric cancer for TNM classification: International Gastric Cancer Association staging project. Gastric cancer. 2017, 20(2):217-225.

\section{Figures}
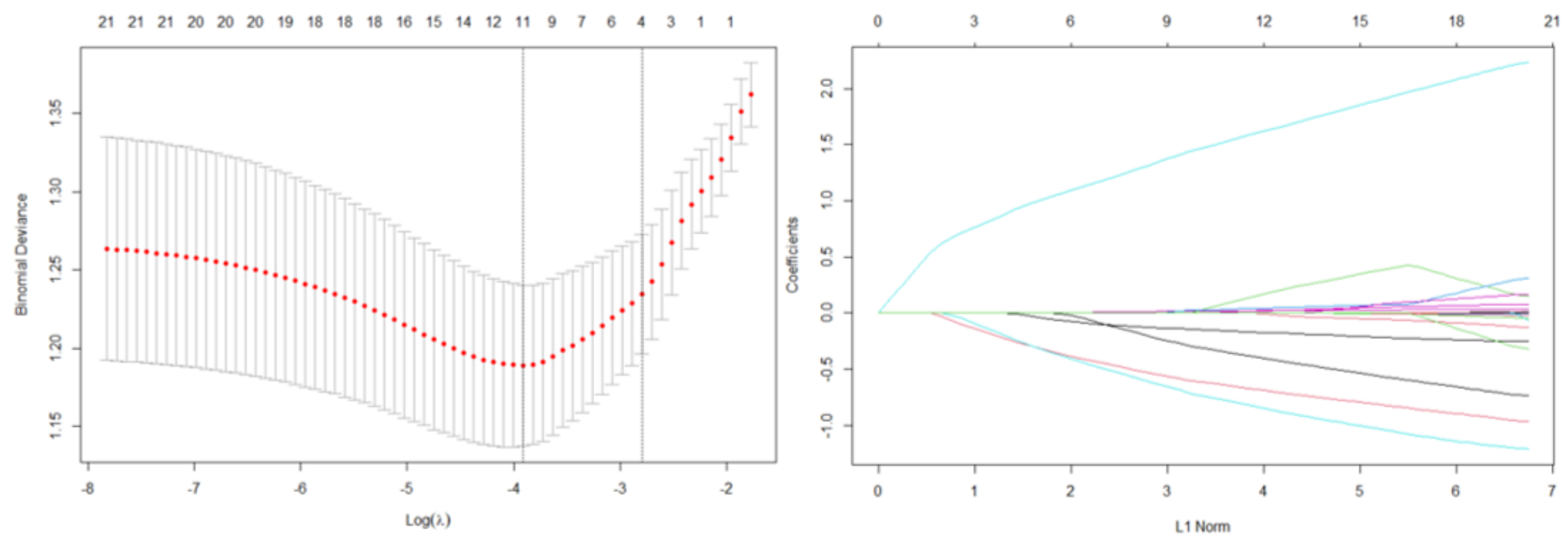

Figure 1

Texture feature selection using the least absolute shrinkage and selection operator (LASSO) binary logistic regression model. 
Points

cT stage

Location

CA724

Tumor differentiation

Total points

NAC response

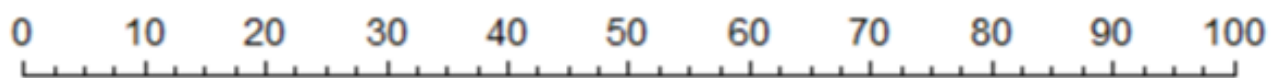

$\mathrm{T} 2$

3

,

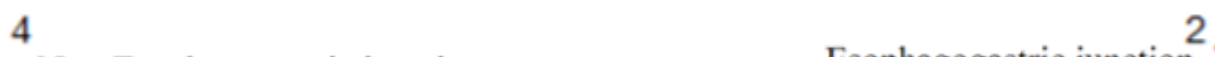

Non-Esophagogastric junction Esophagogastric junction ${ }^{2} 12$

11

$>6.5 \mathrm{U} / \mathrm{mL} \quad<=6.5 \mathrm{U} / \mathrm{mL}^{11}$

12

11 Well+Moderately differentiated

12 Poorly differentiated +

Signet ring cell

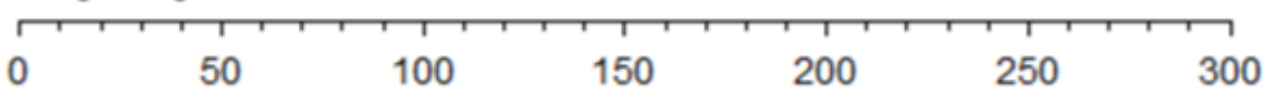

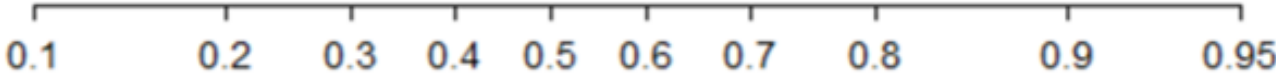

\section{Figure 2}

Nomogram for predicting response to neoadjuvant chemotherapy. 


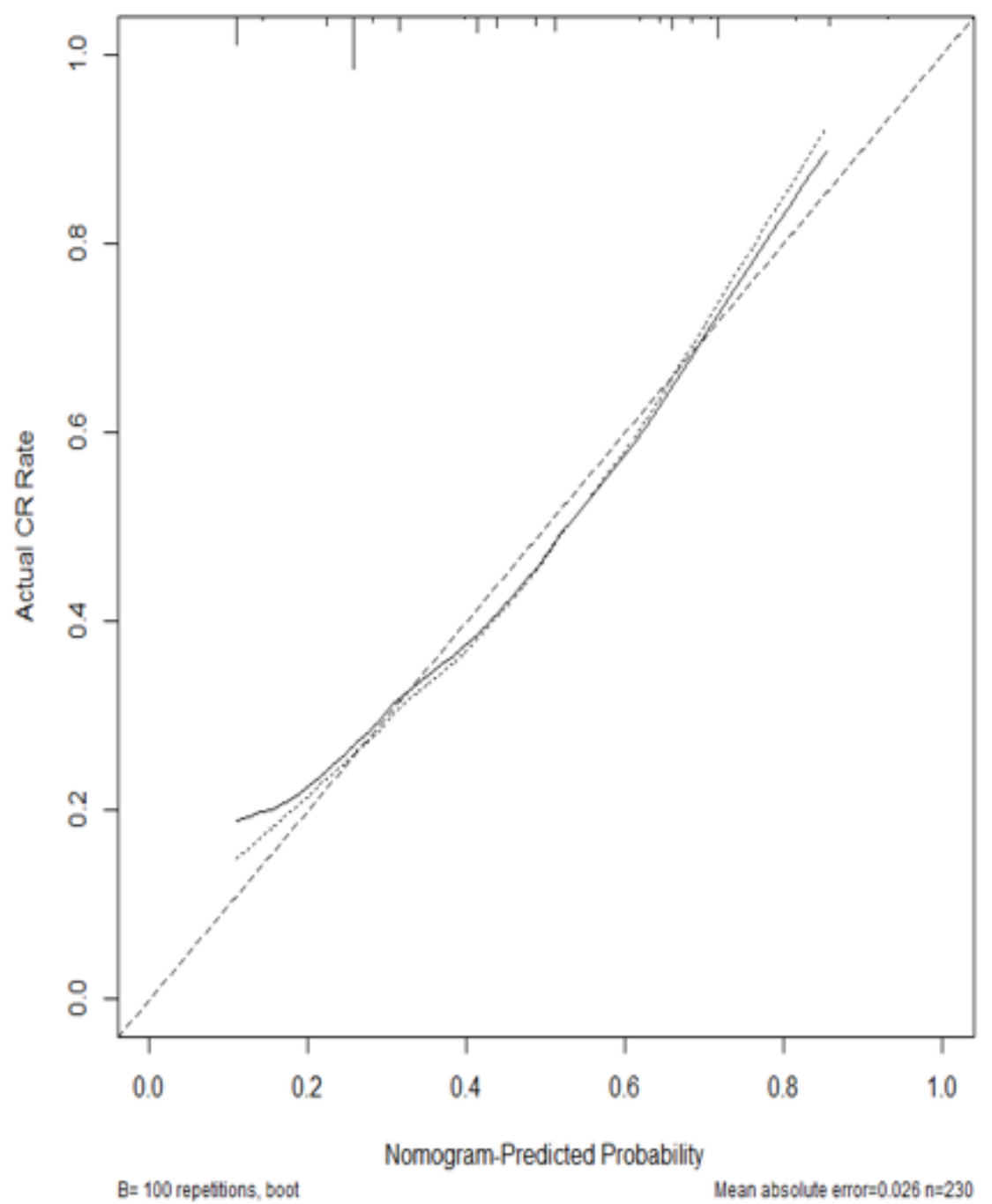

Figure 3

Calibration curve for the nomogram model. 


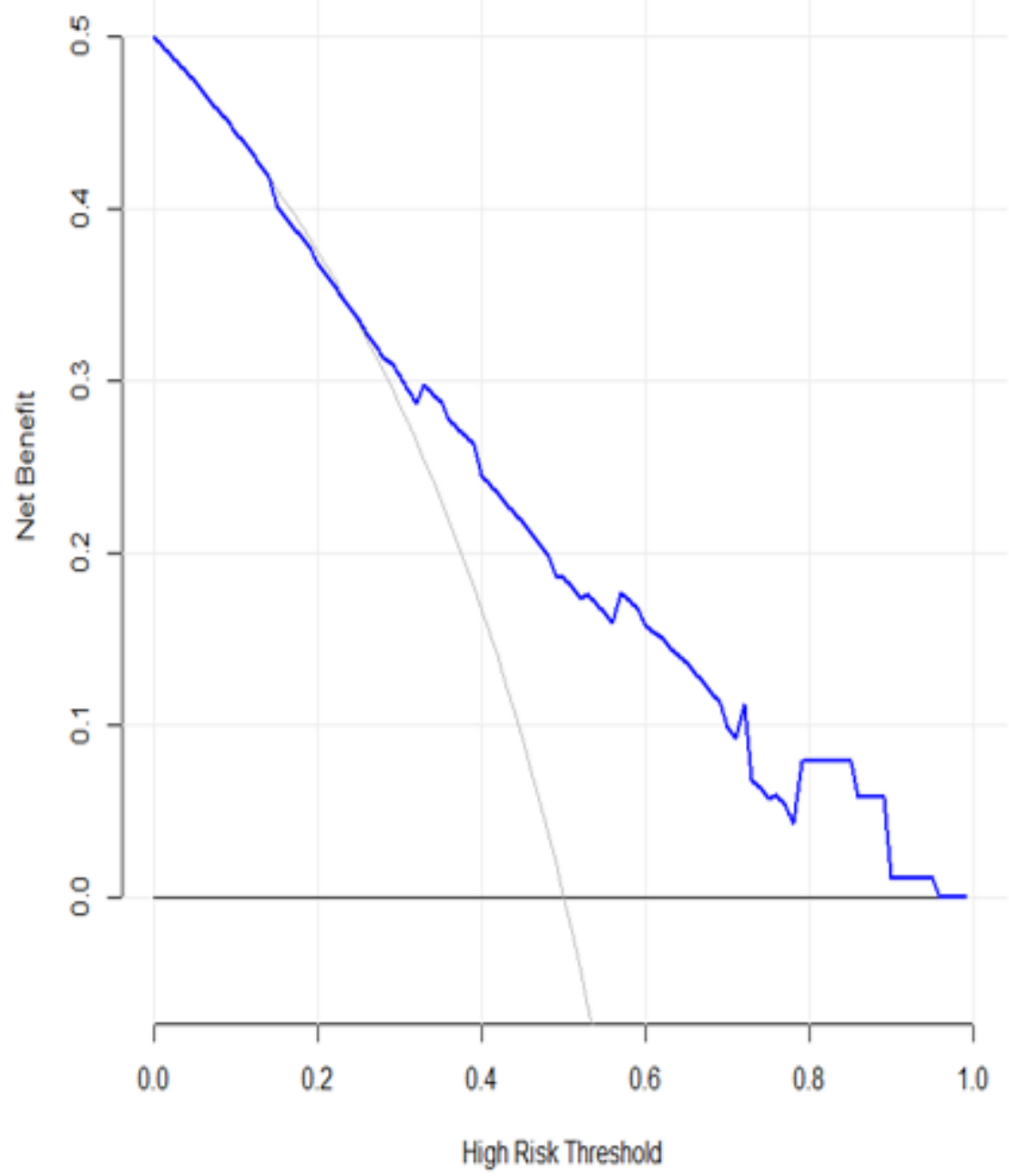

Figure 4

The DCA analyzed clinical utility of the nonogram. The $y$-axis represented net benefits and the $x$-axis measured threshold probability (Pt). The horizontal solid line indicated the advantage for patients not receiving NAT, the oblique solid line represented the advantage for patients receiving NAT and the diagonal dotted line (nomogram) indicated survival on the basis of nomogram scores to resolve whether a patient should receive NAT. A treatment strategy was superior if it had the highest value compared to other models, including two simple strategies, such as performing NAT for all patients (sloping solid line) or performing primary surgery first (horizontal solid line). 